\title{
Digital ist überall
}

Digitalisierung ist das zurzeit wohl am häufigsten zu hörende Buzzword. Früher meinte der Begriff einmal das Umwandeln analoger Formate in digitale - etwa für CD-Versionen ursprünglich analog aufgenommener Musikalben. Heute geht es dabei um den Einzug digitaler Technik in alle Lebens- und Arbeitsbereiche. Die dabei ausgelösten Veränderungen sind umfangreich und betreffen so gut wie alle Branchen.

Während etwa Versicherungen und Banken schon seit Jahrzehnten intensiv mit digitaler Technik arbeiten, ist für viele andere Bereiche das Digitale noch weitgehend Neuland. Personalabteilungen nutzen heute beispielsweise zunehmend digitale Unterstützung bei der Bewerberauswahl - das sogenannte „Robo Recruiting“. Die umfassende Digitalisierung beeinflusst die Zusammenarbeit dabei keineswegs nur in technischer Hinsicht, auch die Organisation und das Miteinander der Kollegen verändern sich - New Work ist hier ein oft zu hörendes Schlagwort. Viele Menschen arbeiten zwar bereits lange mit Computer und Co., aber das Digitale ist dennoch in vielen Köpfen noch nicht angekommen - dafür ist es aber höchste Zeit, damit Deutschland nicht international ins Hintertreffen gerät. Dazu gehört auch, dass uns die nötigen Fachkräfte fehlen, um den digitalen Wandel meistern zu können - eine dringende und wichtige Herausforderung für die Schul- und Bildungspolitik.

Neben den unbestreitbaren Vorteilen, bringt die umfassende Digitalisierung aller Lebensbereiche aber auch neue Risiken mit sich. Insbesondere der Datenschutz und die viel diskutierte Cybersicherheit spielen hierbei eine entscheidende Rolle. Das gilt für jedes einzelne Unternehmen, aber auch für das Land insgesamt, weshalb Norbert Pohlmann im Inter-

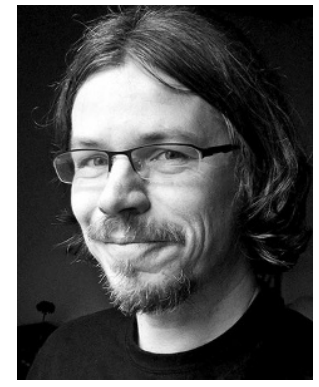

Peter Pagel $(\square)$ peter.pagel@springer.com

\section{Wiesbaden, Deutschland}

view meint „Was wir brauchen ist eine IT-Sicherheitsstrategie für Deutschland“. Vieles ist also in Bewegung, jetzt kommt es darauf an, sich nicht nur treiben zu lassen, sondern die Veränderung aktiv mitzugestalten. Dabei wünsche ich allen Lesern viel Erfolg!

Herzliche Grüße

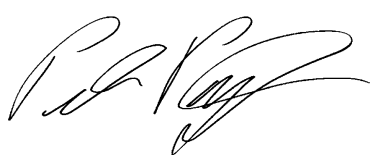

Peter Pagel

Chefredakteur 